\title{
Analysis on the Effect of Shading on the Characteristics of Large-scale on-grid PV System in China
}

\author{
Yunlin Sun, Xiangzhi Li, Ruijiang Hong, Hui Shen* \\ School of Physics and Engineering, Sun Yat-Sen University, Guangzhou, China \\ Email: sunyunlin@163.com
}

Received February, 2013

\begin{abstract}
Because of rich solar resource and low land cost, a lot of large-scale ground-based grid-connected PV systems have been built in Northwest China. In this paper, some shading phenomena on a grid-connected PV system in Northwest China are classified and analyzed. Through the I-V curve test of PV modules, it can be seen that dust influence system performance of the grid-connected PV system. And the experimental results have shown that shading could affect the electrical properties of PV modules. Meanwhile, same shading area on different shading positions could have different impacts on the identical PV module.
\end{abstract}

Keywords: Large-scale; Ground-based on-grid PV System; Shading; System Performance

\section{Introduction}

In the process of actual installation of PV system, there are many influencing factors. Among them, shading which could influence the performance of PV system has aroused common concern and research. PV modules are generally installed in the areas of rich solar resource and vast land. Exactly, Northwest China can provide an ideal environment for PV modules installation because of its widely distributed Gobi, desert and shoals. However, under natural conditions, PV modules would be covered by certain blocks such as leafs and guanos after longtime use. These kinds of objects will form shadows on the modules that would affect the performance of PV modules so that the output power reduces directly $[1,2]$. On the other hand, owing to the difference between preliminary design and actual terrain of PV system, inappropriate distance between front and rear PV arrays would cause shading phenomena too. Like the uneven and rugged surface would also lead to this kind of shading in the actual situation [3].

Obviously, partial shading will change the I-V characteristics of a PV module [4]. The product of current and voltage will increase in some part of the PV module due to the shading, and then temperature of these areas will rise. After longtime use, some areas will become darker on the surface of PV module and this phenomenon is called "hot spot" [5]. Certainly, defects of solar cell itself could also produce heat and bring "hot spot" for PV module even in the normal work [6]. Such cases can re-

\footnotetext{
*Corresponding author.
}

sult in reduction of the output power of PV module, as shadows on partial PV module, uneven irradiance on PV array or mismatching power of PV module in a PV array [7].

\section{Classification of Shading}

According to field research, it can be found that shading phenomena on PV module differ somewhat depending on the specific circumstances such as different regions or PV systems [8]. On the contrary, shades have something in common; they can be the caused by power distribution rooms nearby, the surrounding vegetation, or sometimes the front row arrays [9]. During the construction process, the surface structure and ground condition may not match exactly with design drawings. So PV arrays sometimes can not be at the same height so that the front row shadows would cover the rear row [10].

There are many types of shading phenomena in PV system, and they can be divided into the following categories after longtime surveys and observation on one large ground-based grid-connected PV system.

1) The front row shading phenomenon (Figures 1, 2)

2) The surrounding plant and guano shading phenomenon (Figures 3, 4)

3) The nearby power distribution room and wire pole shading phenomenon (Figures 5, 6)

\section{The Effect of PV Array Shading on Electrical Properties of PV Module}

A PV system is constituted of many PV modules that are 
connected by series and in the parallel way. If the arrays layout is unreasonable or there are shades around the arrays, shading will appear on some modules. In practical situations, a module with shading in a long series will not produce photovoltage, while other modules in the same series still produce voltage normally. So there is current going through this shaded module [11, 12]. However, even current runs through the module, it can not produce a normal output power without photovoltage inside. Because of this reason, the shaded module becomes a load in the string and dissipates power because of the generated heat. So other normal modules need to work at a higher voltage in order to maintain the total voltage of whole series and reduce voltage loss of the shaded module. To the normal modules, the higher voltage will create less current and more output power loss.

Actually, the method usually used to reduce the power loss from partial shading is to divide a string into several parts with some bypass diodes [13]. The part with shaded module will be isolated by the bypass diode from other parts, so the voltage and current of this string will lose in proportion to the shading areas. And the output power of other not shaded parts without being protected by the diode will not lose [14, 15].

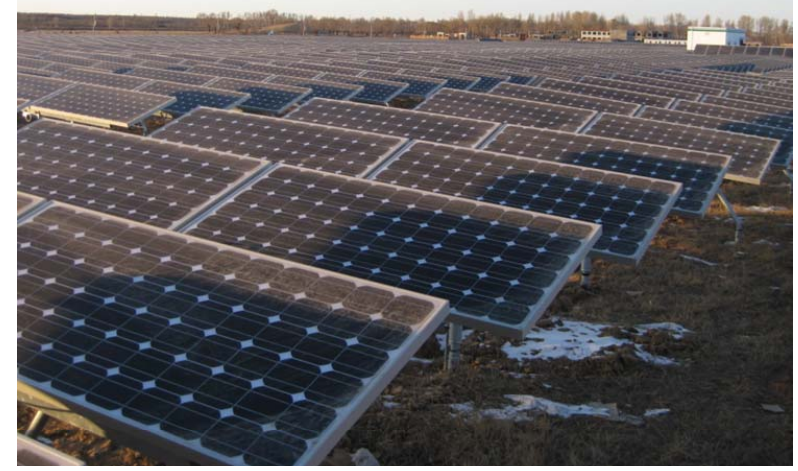

Figure 1. Front row shadows on the rear row in tracking PV system.

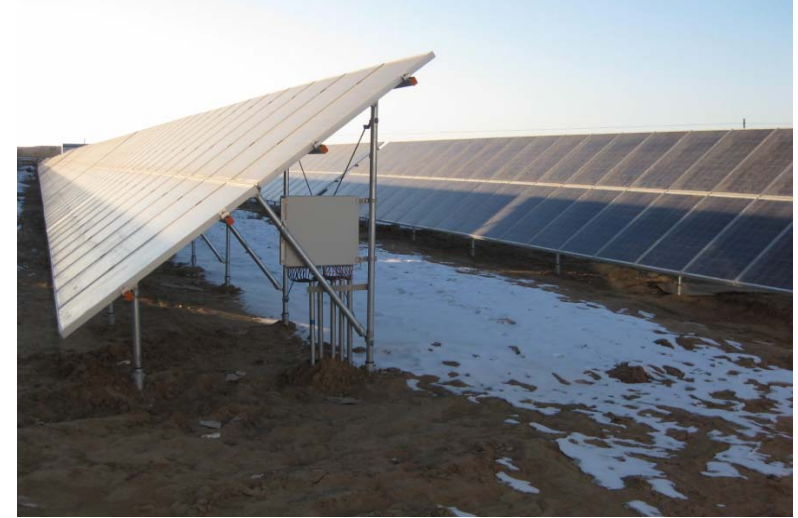

Figure 2. Front row shadows on the rear row in fixed PV system.

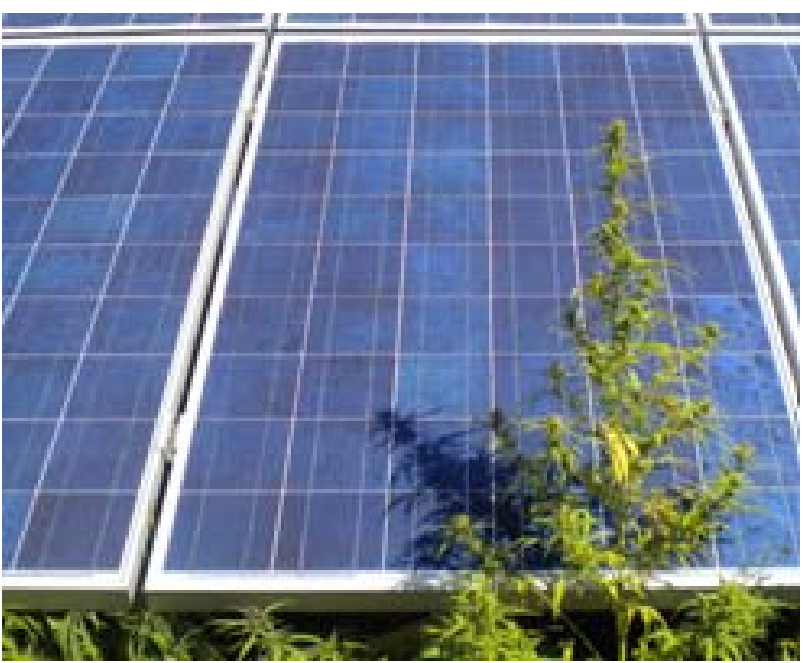

Figure 3. Plant shadows on the PV module.

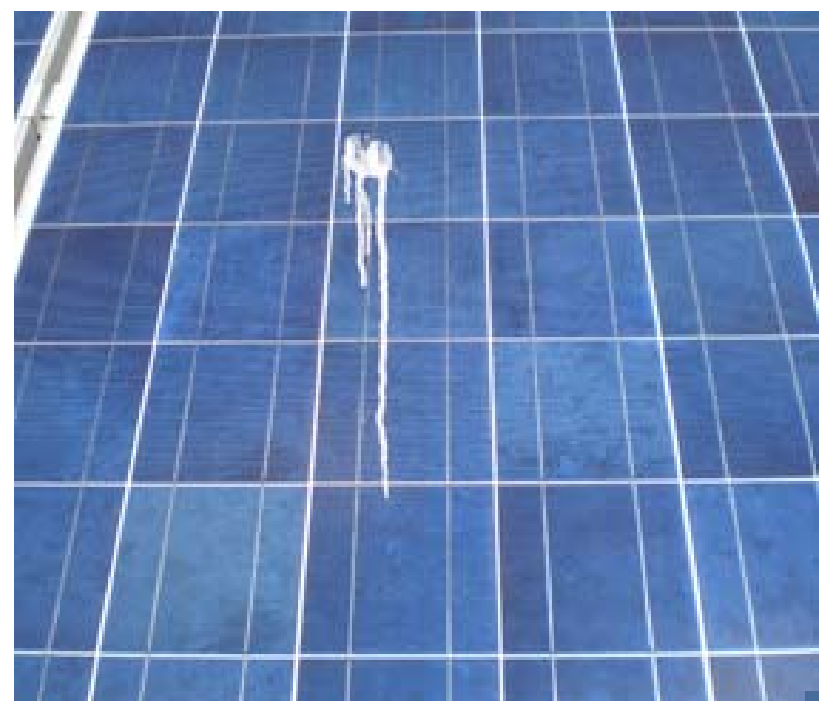

Figure 4. Guano shadows on the PV module.

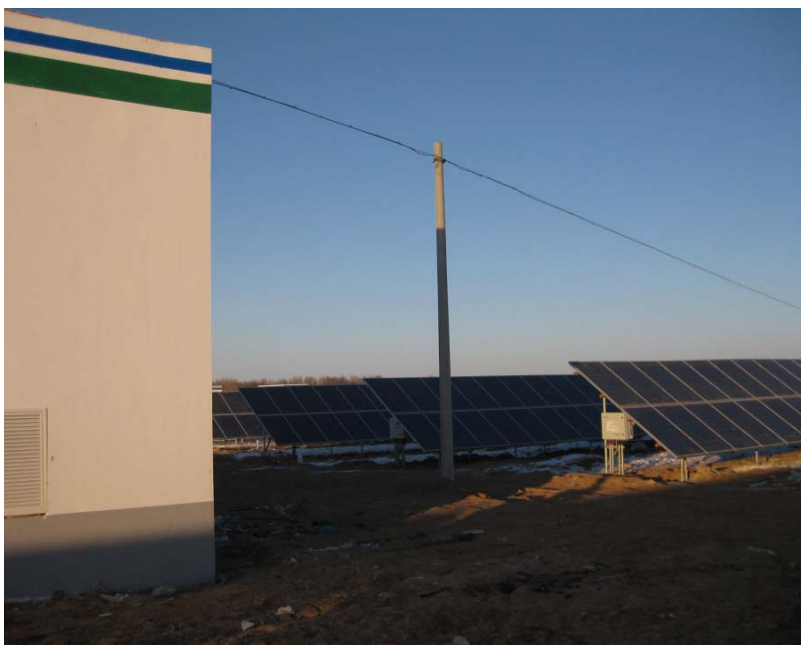

Figure 5. Power distribution room shadows on the PV module. 


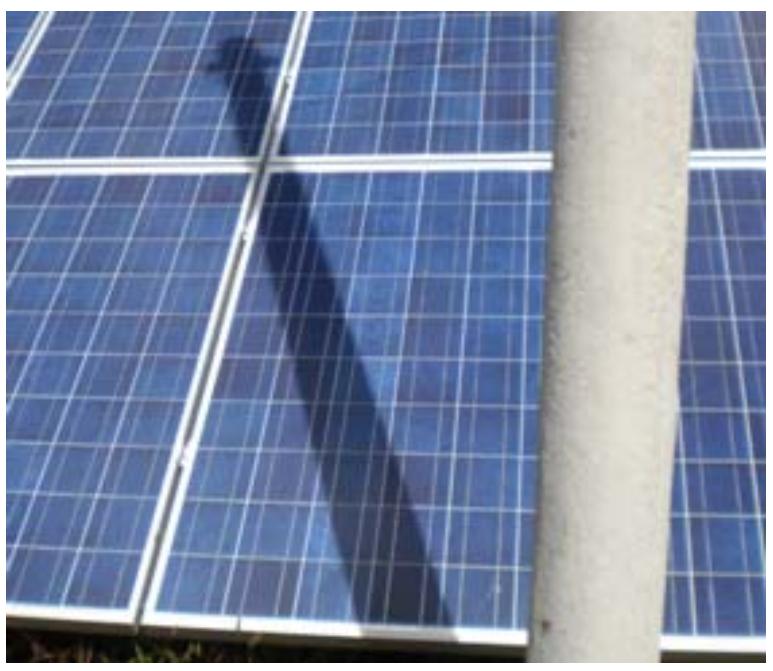

Figure 6. Wire pole shadows on the PV module.

\section{The Effect of Wire Pole Shading on Electrical Properties of PV Module}

In a large grid-connected PV system in Northwest China, aiming at wire pole shading phenomenon, some experiments have been done to analyze the effect of nearby building shading on electrical properties of PV module.

This experiment uses some poly-Si modules produced by a China manufacturer. The module is made up by 60 pieces of solar cells $(156 \mathrm{~mm} \times 156 \mathrm{~mm})$ connected in series. There are three bypass diodes in one module and each diode can protect 20 pieces of solar cells. The nominal parameters of the module are: $P \max =220 \mathrm{~W}$, $V m p p=29.0 \mathrm{~V}$, Impp $=7.95 \mathrm{~A}$, Voc $=36 \mathrm{~V}$, Isc $=8.19$ A.

As the Figure 7 shows, wire pole shadows on PV modules in on-the-spot investigation, and each module is numbered. Figure 8 shows six I-V curves corresponding to six numbered modules.

Combining these two figures, it is shown that there are no shadows on NO.2 and NO.3 module and the electrical properties of them can be maintained. The electrical properties of NO.1, NO.4, NO.5 and NO.6 modules with wire pole shadows on them are affected obviously, and their I-V curves change; as a result, their performances have degraded. However, modules with shadows are not in complete failure because of protections by bypass diodes, and their performances are different along with different shadow position and area. Thus, it can be seen that the properties of PV module not only could be influenced by shades like wire poles, but also change along with the changeable shadow position and area.

\section{Summery}

According to the field investigation results on a large ground-based grid-connected PV system, this paper clas- sifies the common shading phenomena on the grid-con-

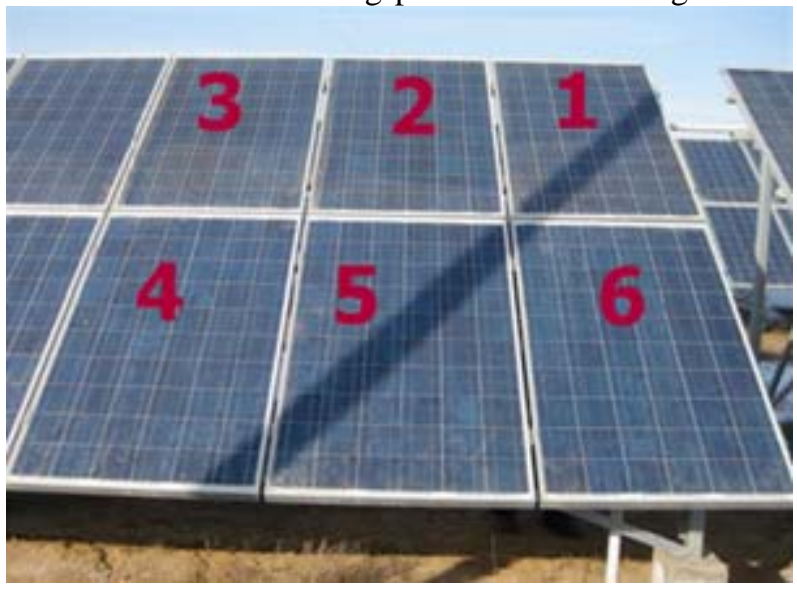

Figure 7. Wire pole shadows on the PV modules.

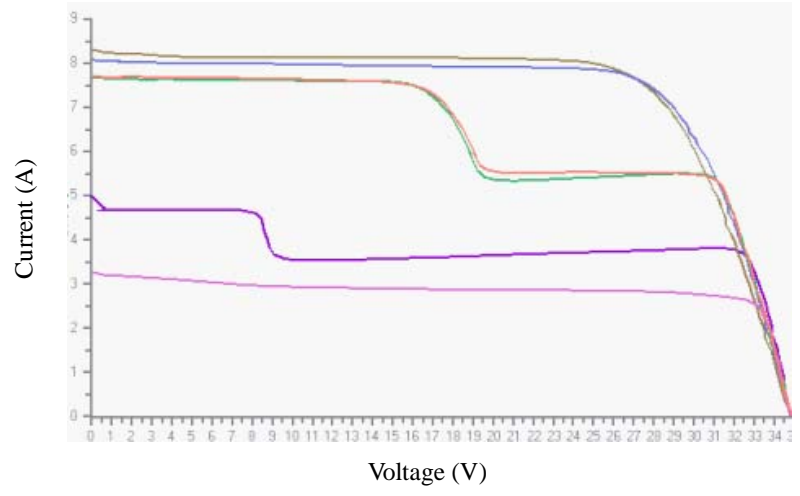

Figure 8. Six I-V curves corresponding to six numbered modules.

nected PV system in Northwest China. They are mainly front row shading, plant and guano shading and nearby building shading. Then, aiming at nearby building shading phenomenon, some experiments have been done. From the experimental results, it can be seen that shading can affect the electrical properties of PV modules. Meanwhile, same shading area on different shading positions can cause different impacts on the identical PV module.

\section{REFERENCES}

[1] K. Morita, et al., "Correlation between the Change of the Appearance and Reduction in the Output Power of Crystalline Si Solar Cell Modules by Outdoor Exposure," Proceedings of JSES/JWEA Joint Conference, 2000, pp. 287-290.

[2] D. Uchida, K. Otani and K. Kurokawa, "Evaluation of Effective Shading Factor by Fitting a Clear-day Pattern Obtained from Hourly Maximum Irradiance Data," Solar Energy Materials and Solar Cells, Vol. 67, No. 1-4, 2001, pp. 519-528.

doi:10.1016/S0927-0248(00)00321-4 
[3] J. Appelbaum and J. Bany, "Shadow Effect of Adjacent Solar Collectors in Large Scale Systems,” Solar Energy, Vol. 23, No. 6, 1979, pp. 497-507.

doi:10.1016/0038-092X(79)90073-2

[4] H. Kawamura, K. Naka, N. Yonekura, S. Yamanaka, H. Kawamura, H. Ohno and K. Naito, "Simulation of I-V Characteristics of a PV Module with Shaded PV Cells," Solar Energy Materials \& Solar Cells, Vol. 75, No. 3-4,2003, pp. 613-621. doi:10.1016/S0927-0248(02)00134-4

[5] A. Woyte, J. Nijs and R. Belmans, "Partial Shadowing of Photovoltaic Arrays with Different System Configurations: Literature Review and Field Test Results," Solar Energy, Vol. 74, No. 3, 2003, pp. 217-233. doi:10.1016/S0038-092X(03)00155-5

[6] J. C. Arnett and C. C. Gonzales, "Photovoltaic Module Hot spot Durability Design and Test Methods," Proceedings of the 15th IEEE Photovoltaic Specialists Conference, 1981, pp. 1099-1105.

[7] E. Karatepe, M. Boztepe and M. Colak, "Development of a Suitable Model for Characterizing Photovoltaic Arrays with Shaded Solar Cells,” Solar Energy, Vol. 81, No. 8, 2007, pp. 977-992. doi:10.1016/j.solener.2006.12.001

[8] M. Meinhardt and G. Crame, "Multi-string-converter- the Next Step in Evolution of String-converter Technology," Proceedings of Evolution of the European Power Electronics Conference, 2001.

[9] M. Drif, P. J. Perez, J. Aguilera, et al., "A New Estimation Method of Irradiance on a Partially Shaded P-V
Generator in Grid-connected Photovoltaic Systems," Renewable Energy, Vol. 33, No. 9, 2008, pp. 2048-2056. doi:10.1016/j.renene.2007.12.010

[10] J. Bany and J. Appelbaum, "The Effect of Shading on the Design of a Field of Solar Collectors. Solar Cells," Vol. 20, No. 3, 1987, pp. 201-228. doi:10.1016/0379-6787(87)90029-9

[11] S. S. A. Chouder, "Effects of Shadowing on Photovoltaic Module Performance,” Progress in Photovoltaics, Vol. 16, No. 2, 2008, pp. 141-149. doi:10.1002/pip.780

[12] P. Spirito and V. Albergamo, "Reverse Bias Power Dissipation of Shadowed or Faulty Cells in Different Array Configurations," Proceeding of the 4th EC PV Solar Energy Conference, 1982, pp. 296-300.

[13] M. C. Alonso-Garcia, J. M. Ruiz and F. Chenlo, "Experimental Study of Mismatch and Shading Effects in the I-V Characteristic of a Photovoltaic Module," Solar Energy Materials \& SolarCells, Vol. 90, No. 3, 2006, pp. 329-340. doi:10.1016/j.solmat.2005.04.022

[14] A. K. Sharma, R. Dwivedi and S. K. Srivastava, "Performance Analysis of a Solar Array under Shadow Condition," IEE Proceedings G Circuits, Devices and Systems, Vol. 138, No. 3, 1991, pp. 301-306.

$\underline{\text { doi:10.1049/ip-g-2.1991.0051 }}$

[15] B. Hu, Y. Nonaka and R. Yokoyama, "Influence of Large-scale Grid-connected Photovoltaic System on Distribution Networks," Automation of Electric Power Systems, Vol. 36, No. 3, 2012, pp. 34-36. 